\title{
Who Is More Trustworthy, Alexa or Mom?: Children's Selective Trust in a Digital Age
}

\author{
Grace W. Murray \\ School of Lifespan Development and Educational Science, Kent State University
}

\begin{abstract}
Children obtain much of their early knowledge informally through first-hand observations (e.g., children as little scientists). Though the "little scientist" approach has a strong history within cognitive development, a newer perspective suggests it is not only independent observation of the environment through which children learn but also by posing questions to trustworthy individuals around them. Now, in a digital age, children can inform their understanding of the world by asking questions not only of adults but also of digital agents who are able to scour the internet and provide quick responses to children's questions. As a result of voicesearch functionalities typically present in digital voice assistants (DVAs; e.g., Alexa), children can query the internet at an earlier age, sidestepping literacy-based prerequisite skills needed for traditional computer search engines. This review examines several child-level and technology-level factors that may influence children's trust in DVAs relative to human informants. No work has combined these lines of inquiry in a way that has extended social (i.e., confidence, benevolence) and epistemic characteristics (i.e., accuracy, expertise) used in human-to-human interaction to digital voice assistant-to-human interaction. Results suggest DVS do not yet meet children's expectations for a trustworthy informant, providing implications to improve DVA functionality for young users.
\end{abstract}

Keywords: selective trust, digital voice assistants, knowledge development

Children ask $a$ lot of questions ( $\sim 1$ question per minute, Chouinard, 2007; Frazier et al., 2009; Lovato et al., 2019). Now, with the increase of internet-based devices, particularly digital voice assistants (DVAs; Beneteau et al., 2019), children have more sources to whom they can direct their many questions, requiring that the field begin exploring when and why children may query internet devices relative to human informants. Most research investigating children's inquiry and trust in informants (i.e., "trust in testimony," see Tong et al., 2020, for review) considers human-tohuman interaction and the characteristics that make one human informant more trustworthy than another. This leaves a large gap in our understanding of children's willingness (or lack thereof) to query and trust digital informants.

Prior work generally considers children's inquiry and trust of internet-based devices broadly (e.g., internet search engines,

Action Editor: Danielle S. McNamara was the action editor for this article. ORCID Ids: Grace W. Murray (D) https://orcid.org/0000-00026652-8348.

Disclosures: We have no conflicts of interest to disclose. The authors declare this review was conducted in the absence of any commercial or financial relationships that could be construed as a conflict of interest. This work is not pending publication at another journal nor has any portion of it been disseminated in any form.

Open Access License: This work is licensed under a Creative Commons Attribution-NonCommercial-NoDerivatives 4.0 International License (CC-BYNC-ND). This license permits copying and redistributing the work in any medium or format for noncommercial use provided the original authors and source are credited and a link to the license is included in attribution. No derivative works are permitted under this license.

Contact Information: Correspondence concerning this article should be addressed to Grace W. Murray, School of Lifespan Development and Educational Science, Kent State University, 405 White Hall, Kent, OH 44242, United States. Email: gmurray5@kent.edu computers, Danovitch, 2019; Danovitch \& Alzahabi, 2013; Wang et al., 2019) with little attention paid to DVAs and the characteristics used to evaluate trust in these oftenanthropomorphized devices (Garg \& Sengupta, 2020; Lovato \& Piper, 2015). Thus, the purpose of the present review is to investigate whether DVAs meet children's expectations for a trustworthy informant, considering the epistemic (i.e., accuracy, expertise) and social characteristics (i.e., benevolence, confidence) traditionally investigated in human-to-human interaction and applying them to human-DVA interaction. No work, to the author's knowledge, has comprehensively combined these lines of inquiry as a means to improve child-DVA interaction and better understand children's knowledge development and selective trust in a digital age.

DVAs are defined here as internet-based devices that respond to human speech sounds by listening for a wake word (e.g., "Siri," "Hey Google"), recording the speech input, sending the input to a server that parses the speech into device-friendly commands, and subsequently, sending an audio file back as a response (see Hoy, 2018, for a review). To answer requests for information, DVAs may (a) scour internet search engines such as Google or Bing, gathering information based on factors such as language (Google, 2021), or (b) rely on crowdsourcing to answer previously unanswerable questions from search engines alone (see Alexa Answers, de Rooij et al., 2019; Wiggers, 2019), allowing humans-particularly children-to gather new information without needing to master literacy-based prerequisite skills. For instance, children can now ask DVAs, like Siri and Alexa, questions about the world much like they would a parent or teacher, sidestepping traditional computer search engines that require the ability to read and write. Thus, DVAs may provide greater accessibility for children's inquiry than other digital devices that do not have voice-search functionalities. Accordingly, this review draws on existing literature from developmental psychology, cognitive science, and human-computer interaction to understand 
how DVA functionalities may interact with the characteristics (i.e., accuracy, expertise, confidence, likeness) children use to evaluate speaker trust. The review is not meant to be exhaustive but selective in its consideration of children's trust in DVAs relative to humans. A brief discussion of children's information-seeking behaviors precedes a discussion of evaluatory characteristics (i.e., accuracy, confidence) to provide background for understanding how and when children may choose to seek information from othersdigital or otherwise.

\section{Children's Information Seeking}

Questions draw attention to gaps in current knowledge, highlighting what children believe to be important in understanding the world around them. Importantly, by asking questions, children initiate a conversation that allows them to not only obtain new knowledge but also evaluate and potentially amend their prior knowledge. At approximately 20 months old, infants can begin to show signs of information seeking not only when they are ignorant (i.e., not knowing the location of a toy) but also when they are not confident about the knowledge they hold (Goupil et al., 2016). This pattern continues, persistently (Chouinard, 2007; Frazier et al., 2009) in early development, with $90 \%$ of infants' questions relating to facts, such as the names or locations of objects and people (Chouinard, 2007). However, this type of query changes drastically before a child's third birthday. By 2 and a half years, approximately a quarter of children's questions requested explanations, and by 3 and a half years, nearly a third to half of the questions requested explanations (Chouinard, 2007). This increase in explanatory requests is important for knowledge development. Children construct much of their early knowledge through informal observation (e.g., the earth is flat), which can lead to the development (and later entrenchment) of misconceived knowledge if not corrected (Bruner, 1957; Marchant et al., 1991; McNeil \& Alibali, 2002). Children are more likely to update prior knowledge when presented with coherent explanations for why their prior knowledge is incorrect and/or misinformed.

When explanations are not provided, children may maintain their own beliefs if they are confident in those beliefs and/or if they have informal, observational data to support those beliefs (e.g., the ground looks flat, so the earth must be flat as well; see Jaswal, 2010). Thus, knowledge development is initially highly malleable (when children know little about the world) but becomes less malleable as information accumulates. This means individuals with more richly developed knowledge structures are more likely to alter environmental input to match their prior knowledge than modify an already existing structure (e.g., Bruner, 1957; Luchins, 1942; Marchant et al., 1991; McNeil \& Alibali, 2002). Consequently, children's explanatory questions, and questions more generally, are an important informal intervention for the development of knowledge.

The sheer number of children's questions increases throughout early childhood (Callanan \& Oakes, 1992; Dunn \& Brown, 1993; Harris, 2012; Hickling \& Wellman, 2001), particularly for Western, educated, industrialized, rich, and democratic (WEIRD) samples (Henrich et al., 2010). Though, perhaps counterintuitively, this behavior drops off when children enter the classroom (Tizard et al., 1983). Children ask far fewer explanatory questions at school than they do at home, making the case that children's questioning behaviors do not increase linearly nor do they function uniformly across all contexts (see Gauvain et al., 2013; Gauvain \& Munroe, 2020 , for differences by socioeconomic status).

Thus, as evidenced above, asking questions promotes learning in a social context (Kurkul \& Corriveau, 2018), but is the same effect achieved if the conversation partner is not human? Much of the seminal work (Chouinard, 2007; Hickling \& Wellman, 2001) investigating children's inquiry hinges on the CHILDES database (MacWhinney \& Snow, 1985), which includes naturalistic recordings of parent-child dyads collected more than two decades ago. While the database has since been updated, the seminal work considers questions and responses that occurred before the widespread prevalence of digital informants, such as the internet and DVAs. This is problematic because technology has drastically influenced not only the type of information that children can obtain but also the rate at which it can be obtained (Danovitch \& Keil, 2008). It is expected that by 2022 , more than $50 \%$ of U.S. households will have at least one DVA (Beneteau et al., 2019). Such increased access may mean changes in the way children seek information in their environment, calling for an updated investigation of how and when children seek information from adults relative to digital devices.

Recent studies suggest children $d o$ ask questions of digital informants just as they ask questions of adults. For example, when parents are asked how their children use voice search, the most frequently reported function is information seeking $(45 \%$, Lovato \& Piper, 2015). And of the questions asked of DVAs, children are most likely to seek out information about science and technology (24\%, "How are pillows made?" "What's the fastest animal in the world?") with culture (21\%, "How old is Leo Messi?" "Do unicorns exist?") and practical questions (18\%, "What's the weather today?") falling closely behind (Lovato et al., 2019). While informative, these findings do little to explain (a) why children chose to seek this information from a digital device rather than an adult and (b) what type of questions children choose to ask of digital devices relative to adults.

Empirical evidence indicating children do indeed query DVAs provides a rationale for subsequent investigation and consideration of digital devices as possible informants for children. However, it is currently unclear whether questioning DVAs is as useful as questioning humans. In order for questioning to be effective for knowledge development, not only do the right questions have to be asked but also the right responses have to be given. Consequently, the following sections review the epistemic (i.e., accuracy, expertise) and social characteristics (i.e., confidence, benevolence) that children use to evaluate potential human informants. The purpose of this investigation is to begin exploring whether DVAs meet children's expectations for a trustworthy informant, providing recommendations for how these devices may be improved to serve young users.

\section{Children's Informant Preferences}

Prior work (Issacs, 1930a, 1930b; Piaget, 1926; Rousseau, 1999) in cognitive development viewed questions as an opportunity to encourage children's autonomous exploration of their environment. Rather than answer a child's question directly, it was believed best to incite independent discovery of the response. In one example provided by Piaget, he described a case in which his daughter 
spun around in circles and consequently asked if he, too, experienced the world spinning. Rather than answer her question, he said, "What do you think?" to which she exclaimed, "You always ask me that!" (Harris, 2012).

The response from Piaget's daughter is indicative of recent findings from the "trust-in-testimony" work investigating children's inquiry: Children ask questions that they want answered (e.g., Callanan \& Oakes, 1992; Frazier et al., 2009). Given this expectation, an important empirical question then becomes how it is that children determine who to trust and what subsequent testimony to fold into prior knowledge structures. One possible answer suggests that young children simply defer to the testimony they are given, accepting informants' testimony as truth regardless of their prior beliefs. While this proposition would allow children to rapidly amass new knowledge, it would leave them vulnerable to misinformation (Jaswal, 2010), as informants are not always accurate in the testimony they provide — even with the best intentions in mind (Grice, 1975).

Thus, developing knowledge relies on a balance between credulity and skepticism. (Harris \& Koenig, 2006; Koenig et al., 2004). Without credulity, it is unlikely children would ask the abundance of questions about the world that they do; however, without skepticism, it is unlikely children would be able to effectively evaluate testimony provided as a response to those questions. Critically when children's prior knowledge of a concept is low, they are more likely to rely on testimony to address gaps in their understanding (e.g., Masson et al., 2011). In deciding who to ask questions of and accept testimony from, children monitor a variety of epistemic and social characteristics for other indicators of competence when they lack the relevant knowledge necessary to directly evaluate an informant's testimony (Stephens et al., 2015).

Considering various characteristics, prior work in the testimony literature predominantly investigates children's judgments of human informants. Though research investigating child-DVA interaction is relatively new, it is important to begin considering how children make use of digital informants relative to humans in their quest to acquire knowledge. Exploratory work suggests that young children do trust DVAs (Druga et al., 2017), but how and why is not well understood. It is an open question whether the same characteristics used to evaluate humans are applied to digital informants. The subsequent sections review what is known about the characteristics children predominantly consider when evaluating informant competence (see Table 1), comparing human and digital informants in their ability to aid knowledge development.

\section{What You Say Matters}

\section{Accuracy}

Children's ability to evaluate humans' accuracy increases as they age and gain domain knowledge (Einav \& Robinson, 2010; Pasquini et al., 2007). Preschoolers (3-4 years old) are more likely to accept an informant's testimony regardless of its accuracy relative to older children (e.g., 5-year-olds, Jaswal et al., 2014). For instance, 3- and 4-year-olds trust "helpers" and "trickers" at equal rates (Vanderbilt et al., 2011, p. 1372). However, despite their failure to consistently endorse helpful informants, 4-year-olds acknowledge that previously helpful informants would likely be better able to provide accurate information. Three-year-olds do not make this assessment, suggesting 4 years of age may be a transitional period in the development of an accuracy heuristic (Tong et al., 2020). This supposition is underscored by data showing 5-year-old children can override the tendency to trust both helpers and trickers, trusting helpful informants significantly more often in their ability to provide accurate information (Vanderbilt et al., 2011). Older children's increased deference to accurate informants may be a function of their ability to monitor informants' accuracy longitudinally. Beginning at age 4, children are more likely to survey a human's relative accuracy over multiple instances of testimonial feedback, forgiving instances of inaccuracy if the informant is predominately accurate (Pasquini et al., 2007; Ronfard \& Lane, 2018). Thus, older children

\section{Table 1}

Reviewed Variables That Affect Children's Likeliness to Trust Informant Testimony

\begin{tabular}{|c|c|c|}
\hline Concept & Variables & Effect on information seeking \\
\hline \multirow[t]{11}{*}{$\begin{array}{l}\text { Children's acceptance or } \\
\text { neglect of testimony }\end{array}$} & \multirow[t]{3}{*}{ Age } & $\begin{array}{l}\text { Young children more likely to display a bias to trust what they are told (Jaswal, 2010; Jaswal et al., } \\
\text { 2014; Ma \& Ganea, 2010) }\end{array}$ \\
\hline & & $\begin{array}{l}\text { Increased ability to override bias to trust testimony from others as children age (Harris \& Koenig, 2006; } \\
\text { Jaccard, 1981; Jaswal, 2010; Ma \& Ganea, 2010; Tamis-LeMonda et al., 2008) }\end{array}$ \\
\hline & & $\begin{array}{l}\text { Disbelief in an informant's counterintuitive, unexpected testimony becomes more pronounced } \\
\text { with age }\end{array}$ \\
\hline & \multirow[t]{6}{*}{$\begin{array}{l}\text { Informant epistemic } \\
\text { characteristics }\end{array}$} & $\begin{array}{l}\text { Preference for accurate informants increases as children age (Einav \& Robinson, 2010; Harris, 2012; } \\
\text { Pasquini et al., 2007; Vanderbilt et al., 2011) }\end{array}$ \\
\hline & & $\begin{array}{l}\text { Children are better able to evaluate digital-informant accuracy at a younger age than human informant } \\
\text { accuracy (Danovitch \& Alzahabi, 2013) }\end{array}$ \\
\hline & & Preference for digital informants increases as children age (Noles et al., 2015; Wang et al., 2019) \\
\hline & & Preference for knowledgeable informants (Birch et al., 2008; Lutz \& Keil, 2002) \\
\hline & & $\begin{array}{l}\text { Preference for confident informants (Jaswal \& Malone, 2007; Sabbagh \& Baldwin, 2001; Sabbagh \& } \\
\text { Shafman, 2009) and informant testimony that adheres to a consensus (Chan \& Tardif, 2013; Corriveau } \\
\text { \& Harris, 2010; Fusaro \& Harris, 2008) }\end{array}$ \\
\hline & & $\begin{array}{l}\text { Preference for kind, benevolent informants (Fu et al., 2015; Lane et al., 2013; Mascaro \& Sperber, } \\
\text { 2009; Nguyen et al., 2016; Pesch et al., 2018) }\end{array}$ \\
\hline & \multirow[t]{2}{*}{ Child characteristics } & $\begin{array}{l}\text { Low prior knowledge means children are more likely to rely on informant testimony (Masson et al., } \\
\text { 2011; Stephens et al., 2015) }\end{array}$ \\
\hline & & $\begin{array}{l}\text { The more confident children are in their self-generated beliefs, the less likely they accept testimony } \\
\text { from others (Karmiloff-Smith \& Inhelder, 1974; Shtulman, 2017) }\end{array}$ \\
\hline
\end{tabular}


may be more inclined than children under the age of 5 years to trust the testimony of a human informant if they observe that informant predominately providing accurate information.

As for digital informants, children as young as 3 years old consistently choose a reliable, accurate digital informant over an inconsistent, inaccurate digital informant (Danovitch \& Alzahabi, 2013), diverging from work investigating human informants such that young children appear to be able to override their accuracy bias earlier with digital informants than human informants. This work replicates a traditional trust-in-testimony paradigm - in which children watch videos of an adult seeking information from other adults; the difference in Danovitch and Alzahabi's study was that they manipulated a computer search engine's accuracy (rather than a human's) across trials to determine whether accuracy serves as a domain-general heuristic for assessing truth. Though more work is needed to generalize these findings, they do imply accuracy may be a characteristic used to evaluate competence for both human and digital informants. Danovitch and Alzahabi (2013) do not provide data to explain why young children are able to override their bias for digital informants at an earlier age than for humans. It may be due to the perception that characteristics of digital informants are more stable and thus more easily tracked than human characteristics (Mikropoulos et al., 2003) or it may merely be a product of the sample, as no other studies manipulate the accuracy of digital informants to test children's trust in digital testimony. Absent of any manipulation, work surveying children's perceptions of digital informants reports that older children, age 6 and beyond, are more likely to believe that digital informants are omniscient than children younger than 6 and thus believe digital agents are more accurate than humans in the testimony they provide (e.g., Danovitch, 2019; Van Duuren et al., 1998).

Researchers have considered whether children will choose to accept testimony from a human or digital informant but without manipulating the informant's relative accuracy (or other characteristics), it is unknown why children would choose one informant over the other without broad speculation. For instance, when presented with a choice to seek out information from a teacher, a peer, or an unspecified internet source, kindergarteners and second graders are more likely to endorse scientific information from a teacher or the internet than a peer with no preference differences between teachers and technology. Adults, however, typically endorsed information provided by the internet (Wang et al., 2019). This finding is underscored by adults' relative confidence in their ability to use internet devices effectively as well as parse out correct, relevant information from incorrect, irrelevant information (Danovitch, 2019). Though these findings appear to detect a developmental transition in source preference, a longitudinal study is needed to confirm.

As advancements in technology continue to blur the distinction between technological and social beings (e.g., uncanny valley, see Mori et al., 2012), we must continue to reevaluate this question of source preference and timing. Based on the findings reviewed here, it may be the case that as individuals age, they begin to acknowledge the limits of human cognition, making them more likely to accept testimony from DVAs than humans because they expect digital informants to buck the limits of human memory and thus be more accurate. However, this expectation has not necessarily come to fruition, as DVAs do not always provide accurate responses (e.g., Lovato et al., 2019) and certain DVAs have demonstrated greater accuracy than others (e.g., Alexa is more accurate than Cortana when providing health information, Ferrand et al., 2020).

Eisen and Lillard $(2016,2017)$ report that younger children tend to be more skeptical of digital informants than older children, initially testing the interface by asking DVAs questions for which they already know the answer (Garg \& Sengupta, 2020; Yarosh et al., 2018). It may be that this initial skepticism is what enables children to evaluate the accuracy of digital informants at a younger age (Danovitch \& Alzahabi, 2013) than they do with humans, suggesting that perhaps training children to utilize a similar strategy with humans may allow them to override their early bias to defer to the information that they are told. However, with the data that are currently available, this is but one hypothesis in a sea of mixed findings. The notion that younger children are more likely to accept human-informant testimony regardless of accuracy (e.g., Jaswal, 2010; Ma \& Ganea, 2010) directly contradicts what is observed when children interact with digital informants (e.g., requiring that DVAs prove their accuracy before trusting responses, Yarosh et al., 2018). As a result, it is unclear whether these are generalizable, sustainable trends in children's trust or whether they are a result of the samples.

\section{Expertise}

In choosing who to accept testimony from, children also consider the division of cognitive labor (Keil et al., 2008), not only recognizing that some informants are more knowledgeable about certain subjects than others but also using it as a heuristic in determining who to trust (Birch et al., 2008; Lutz \& Keil, 2002). For instance, when expertise is manipulated, children between 3 and 8 years old consistently choose to believe claims made by knowledgeable humans with pertinent expertise relative to knowledgeable humans with irrelevant expertise, indicating children are not only aware of expertise but also make decisions based on expertise.

The question then becomes who is perceived as having more expertise, humans, or DVAs? As children age, they become increasingly likely to choose a digital informant over a human with a sharp increase in preference for digital informants around the age of 5 (Noles et al., 2015). Again, it could be that as children age, they come to realize that human knowledge is more constrained than that of digital informants (Danovitch \& Keil, 2008). Digital informants can provide information on myriad topics in seconds, resulting from access to more information than could ever be stored and retrieved within the human brain. That said, it is unclear whether children perceive digital devices as having "expertise" like that of humans.

Some children perceive DVAs as "smart," while others are not so sure: A qualitative investigation of children's perceptions of Google Home reveals half of the children sampled believe Google Home to be "smarter" than they are because it knows more facts; conversely, the other half of children believed they are smarter than Google Home because they are better than the DVA at solving problems (Lovato et al., 2019). This discrepancy provides a potential answer to the question of expertise. Expertise, at least to some children, requires more than just a mere aggregation of facts.

Evidence that children classify expertise as a characteristic that extends beyond fact recall is supported by work investigating the differences between experts and novices. Experts are better able to solve problems and provide explanatory information than 
nonexperts because they understand a concept or problem's deep structure (Ericsson, 2017), allowing them to better provide multiple explanations of the same phenomenon. This ability to adapt responses based on audiences is not suggested to be synonymous with expertise but meant to describe a skill that may prove beneficial considering children's general question-explanation-follow-up sequence (Kurkul, 2015). When an explanation is not provided, or if the explanation is beyond the child's present knowledge state, children are likely to persist in asking the question again - and again (Frazier et al., 2009).

Humans are more likely to possess-or at least explain-deep structure in a way that is digestible for children because they can reframe their explanations based on child-related factors (e.g., limited knowledge). Digital informants, conversely, treat all interlocutors the same, failing to respond based on pedagogical intent or prior knowledge (Csibra \& Gergely, 2009) and failing to respond to children's (5 and 6 years old) how and why questions $50 \%$ of the time [ $8 \%$ partial answers; $14 \%$ no answer; $22 \%$ refusal to answer (DVA indicated it could not answer the question), $6 \%$ not reported, Lovato et al., 2019]. When the input is unclear to a DVA or a repetitive question is asked, DVAs are likely to provide verbatim responses, regardless of whether the question was repeated because the DVA's initial response was incomprehensible (Lovato et al., 2019). This poor performance may be a significant blow to children's selective trust in DVAs because they cannot meet the same standard for providing explanations as humans.

The speculation that children may be less likely to selectively trust DVAs-resulting from the failure to provide explanation-needs additional data to be confirmed. No work, to the author's knowledge, directly compares question types between humans and DVAs. However, the indication that humans and DVAs differentially provide explanatory information to children suggests empirical comparison between informants may be fruitful, particularly because failure to provide consistent explanatory responses could undermine one of the primary advantages DVAs should have over humans: the ability to answer questions quickly and accurately, resulting from their access to vast amounts of information (Tabassum et al., 2019).

In one illustrative case, a child asked Google Home how paper was made four times over the course of 3 days. The first time the child asked, Google Home provided her with information about how to make paper airplanes. Each subsequent time, the child received the following:

On the website wonderopolis.org, they say: To make paper from trees, the raw wood must first be turned into pulp. Wood pulp is a water soup of cellulose wood fibers, lignin, water, and the chemicals used during the pulping process (Lovato et al., 2019, p. 307).

While this response partially answered the child's question, it lacked a coherent, child-friendly explanation, resulting in multiple requests for the same information because the child felt the DVA never provided a satisfactory response (Frazier et al., 2009; Schulz \& Bonawitz, 2007). Empirical studies are just beginning to explore DVA-child interactions, so it is unclear whether the child would have received a different response from an alternative DVA. However, the little work that does exist suggests DVAs are not consistent in providing complete explanatory responses to children's questions (50\%, Lovato et al., 2019) despite correctly transcribing children's questions nearly $90 \%$ of the time, implying that error exists in either how the child asks the question or how the DVA understands it. Perhaps due to linguistic errors, DVAs, while able to transcribe the questions, cannot apply their algorithms to questions asked outside mature linguistic patterns.

Exploratory studies indicate some support for the supposition that children's inquiry skills may, in some cases, not be advanced enough to successfully query DVAs, documenting a trend in which parents frequently help children reformulate questions so they are comprehensible for DVAs (Beneteau et al., 2019; Cheng et al., 2018) because DVAs respond to adults with greater ease (Yarosh et al., 2018). Thus, even though children may possess the ability to query DVAs at a younger age than traditional digital informants, these findings highlight that DVAs were not created with children as their primary audience. While it does appear that training children to ask better questions can lead to more successful interactions between children and DVAs (Beneteau et al., 2019; Yarosh et al., 2018), this training is an extra step that is not required as frequently in human-to-human interaction because humans can consider contextual and/or sequenced information that DVAs cannot. However, it is unclear whether the need for this training would deter children from seeking information from DVAs.

\section{Summary}

Because accuracy and expertise are used by children to evaluate human informant trustworthiness, both were necessary characteristics to consider when evaluating DVA trustworthiness. It was anticipated that DVAs would display greater accuracy and expertise than humans due to the vast amount of knowledge they have access to-relative to humans-but the findings reviewed here indicate otherwise.

Young children $(<4$ years) are more likely than older children to display a robust, inherent bias to trust what they are told (Jaswal, 2010; Ma \& Ganea, 2010; Tong et al., 2020). For instance, young preschoolers consistently trust previously deceptive, inaccurate human informants (Jaswal, 2010, 2014; Vanderbilt et al., 2014). Such deference could be due to an adaptive, but naive, belief that adults' role is to keep children's best interests in mind or perhaps due to the protracted developmental trajectory of cognitive functions, such as the theory of mind and inhibitory control (e.g., Carlson et al., 1998, 2002; Williams et al., 1999). Nonetheless, when evaluating human informants, accuracy and expertise appear to be epistemic heuristics that children rely more heavily on as they age (e.g., $>4$ years, Tong et al., 2020).

DVAs have access to more information at their disposal (i.e., the internet), meaning they are expected to display the abundance of knowledge and consistent prior accuracy (Tabassum et al., 2019) that children look for when evaluating an informant (Einav \& Robinson, 2010). This wide range of information may be useful in abating children's many questions if the information provided via the DVA is (a) correct, (b) explanatory, and (c) takes children's prior knowledge into account. However, the work reviewed here suggests that DVAs are not consistently able to meet these characteristics. While DVAs can provide factual information readily (e.g., What is the weather?), they are less able to provide child-friendly, explanatory information (e.g., Why do labradoodles live longer than golden retrievers?, Lovato et al., 2019). Further, unlike humans, DVAs cannot yet follow sequenced conversations or reframe their responses to inquiries. This may be a fruitful area of development 
for DVAs because children generally ask follow-up questions when a first response is incomprehensible or not given. Currently, DVAs are likely to just repeat the same response to repeated inquiries or state their inability to respond to the request (Lovato et al., 2019). Thus, children, particularly older children ( $>5$ years), may initially trust DVAs more than humans because they are believed to have access to more information and thus may be more accurate. However, when DVA functionalities do not consistently meet children's epistemic expectations for a trustworthy informant, children may be less inclined to continue querying these devices in the future.

\section{But, It Is Not Only What You Say. It Is Also How You Say It \\ Confidence and Consensus}

DVS are distinguishable from other types of technology (e.g., internet search engines) because humans can interact with the devices in a human-like manner via the voice-search function, asking questions of the devices much like one would ask questions of a fellow human and therefore avoiding literacy-based prerequisites (Hoy, 2018; Lovato et al., 2019; Pan et al., 2007). Importantly, the characteristics that make DVAs distinct, also create a situation that allows for an increased likelihood of personification and anthropomorphization of the technology - with greater personification leading to greater social interactions (Druga et al., 2017; Purington et al., 2017). As a result, considering not only epistemic characteristics (reviewed above) but also social characteristics (e.g., confidence, morality, likeness) is necessary when determining how children make trust judgments between humans and devices.

The more confident an informant is in their testimony, the more likely children are to accept the testimony in light of their prior knowledge (e.g., Jaswal \& Malone, 2007; Sabbagh \& Baldwin, 2001; Sabbagh \& Shafman, 2009). Confidence can be communicated by a number of sociopragmatic cues including tone, posture, and word choice. Simply adding "I think" to testimony leads 3-yearolds to become skeptical of provided responses (Jaswal \& Malone, 2007) whereas acknowledging that the testimony is unexpected by adding "You're not going to believe this" leads to greater likelihood of response acceptance (Jaswal, 2004). The framing informants provide to their testimony can elicit longitudinal effects in children's beliefs. For example, children are more confident in scientific entities (e.g., germs) than supernatural entities (e.g., angels), which is hypothesized to be due to how these invisible entities are talked about. When discussing supernatural entities, adults are more likely to frame their testimony with statements such as "I believe." For instance, it is far more likely a child would hear someone say, "I believe in God" than "I believe in germs." The phrase "I believe" and others like it suggest that others doubt the existence of that supernatural entity, and children attend to this doubt in their evaluation of that informant's testimony (see Harris, 2012, for review).

Children are also more likely to trust a claim made by a group of individuals rather than a singular dissenter (Fusaro \& Harris, 2008) because they are largely sensitive to a consensus (Chan \& Tardif, 2013; Corriveau \& Harris, 2010). Phrases such as "I believe" or "I think" suggest a consensus about that concept or entity does not exist; the phrases inherently imply others do not believe or think in that way, and children take note. A common example of this phenomenon is how individuals interpret scientific knowledge and evidence. Skepticism is inherent to the advancement of scientific knowledge. In fact, the scientific method itself requires the continual challenge of existing theories to slowly accumulate knowledge via observation and experimentation. Thus, value exists in skepticism; however, trouble does too. Openness to alternative explanations for scientific findings is often misconstrued by those outside of science as doubt (e.g., Allum et al., 2008).

In the case of digital informants, perhaps they are less likely to give away latent doubts than humans, relying only on facts and commonly supported findings. If an individual asked Siri whether climate change was real, Siri would respond with "Here is what I found": and present the user with several links to webpages for Forbes, NASA, and the World Wildlife Fund. Whereas, if an individual asked Alexa whether climate change is real, Alexa would respond with:

A 2016 paper in Environmental Research Letters states that 97\% of scientists agreed that global temperatures have increased over the last 100 years; $84 \%$ say they personally believe human-induced warming is occurring; and $74 \%$ believe currently available scientific evidence substantiates its occurrence.

Both responses provided by the DVAs do not indicate a consensus. Siri's failure to provide a clear answer to the question could be interpreted as an indication that a consensus does not exist. Further, Alexa's citation, despite the referenced paper being titled "A Consensus on Consensus" (Cook et al., 2016), explicitly states that all scientists do not believe climate change to be a real phenomenon, as none of the reported percentages are $100 \%$.

However, one could argue that young children would be less likely to possess the requisite domain knowledge necessary to ask about climate change. So, what if a child asked Siri whether the earth is flat? When asked this, Siri responds with a simple "no," suggesting Siri may provide differential responses based on whether a consensus exists regarding the asked-about phenomenon. Empirical evidence is necessary to further explore the anecdotal evidence provided here; though, it does suggest that even despite DVAs' nonhuman essence, they still can divulge human-like doubt in the responses that they provide. Such is the case when asked about magical entities like unicorns. When asked whether unicorns exist, Google Home responded with "I believe in unicorns" (Lovato et al., 2019), suggesting, yes, doubt can still be disclosed. It is possible to argue that DVAs are simply parroting back information from search engines, but it is how this information is packaged that conveys confidence.

Children (and adults) do not have a strong conceptual understanding of the internet and how it functions, despite being exposed to internet-based devices starting at birth (Danovitch, 2019). And though some work suggests children (ages 3-5 years old) understand computers are not alive (Mikropoulos et al., 2003), other work argues these devices are still anthropomorphized by children as old as 10-14 years of age (e.g., Kodama et al., 2017), providing contradicting evidence of how children perceive DVAs and their motives (e.g., theory of mind). Combining children's failure to understand internet functionality and some evidence of digital device anthropomorphization, it is indeed plausible to suggest children could interpret DVA responses (e.g., "I believe," "74\% believe") as conveying doubt and/or a lack of confidence in its testimony. That lack of confidence may be what inherently undermines 
children's willingness to trust DVA testimony (Basu, 2019). More research is needed to (a) determine DVAs' typical framing for questions about magical entities or contentious debates and (b) indicate whether children are more likely to accept testimony on these topics from DVAs or humans, as confidence has not been manipulated between informant types.

\section{Morality and Likeness}

DVAs are likely to be personified because humans can interact with them much like they are able to interact with fellow humans, leading to more social interactions between humans and DVAs than other technological devices (Druga et al., 2017; Purington et al., 2017). Younger children are more likely than older children to personify DVAs (Garg \& Sengupta, 2020; Lovato \& Piper, 2015) and use social characteristics to evaluate informant trustworthiness, making perceived confidence, benevolence, and morality important factors to consider when evaluating DVA trustworthiness. It was anticipated that the more familiar and/or sociable the devices were, the more likely that children would be to trust the devices.

Children are more likely to trust an informant who has displayed acts of benevolence (Mascaro \& Sperber, 2009; Nguyen et al., 2016) or been deemed benevolent by others (Lane et al., 2013; Pesch et al., 2018) relative to an observed- or suspected-malicious informant. The inclination to trust a kind or honest informant increases throughout early childhood with persistent effects into middle childhood. Children between six and 11 years old are more likely to differentially weigh testimony based on the informant's intent (Fu et al., 2015). Younger children ( $<4$ years, Tong et al., 2020), however, tend to trust testimony from a nice, honest informant regardless of whether the informant has relevant information or expertise (Lane et al., 2013), meaning that testimony conflicting children's prior knowledge is likely to be accepted from nice informants regardless of whether they are actually knowledgeable about the topic. For instance, when Lane et al. (2013) manipulated trait valence (i.e., meanness or niceness) so it conflicted with knowledge access, children under 5 years old were more likely to report nice informants were knowledgeable even when they lacked adequate access to information.

When children lack information about an informant's morality, they use familiarity or group membership to determine competence, as individuals often ascribe moral warmth to familiar or in-group members (Fiske et al., 2007; Stephens et al., 2015). For example, young children typically endorse testimony from a parent relative to a stranger (Corriveau et al., 2009, 2009) and a native-accented, conventionally speaking informant relative to a foreign-accented, nonconventionally speaking informant (Corriveau et al., 2011; Kinzler et al., 2011). However, as children age, they become more likely to use epistemic characteristics, such as accuracy, to determine trustworthiness relative to social characteristics (Harris, 2012; Tong et al., 2020). For instance, 5-year-olds quickly abandon trust in a caregiver when the caregiver demonstrated consistent errors (Corriveau et al., 2009).

Because digital informants are not inherently human, it is unlikely that they could be intentionally benevolent or malicious. Nonetheless, that does not mean they are without bias. The algorithms speech-recognition systems, like DVAs, operate on do show preferences for certain types of individuals, responding to men with greater ease than women (West et al., 2019); White individuals with greater ease than Black individuals (Koenecke et al., 2020); and adults with greater ease than children (Yarosh et al., 2018). Speechrecognition systems also are unabashed in providing search results that favor certain groups over others (Barocas \& Selbst, 2016; Caliskan et al., 2017; Sweeney, 2013). Such issues may be compounded by how children view DVAs: What happens when children personify these devices, attaching human-like qualities to the machines? Are they held to the same moral standard as humans? Recent work suggests DVA personification has implications for morality.

Young children $(\sim 3-4$ years old) personify DVAs more frequently than older children ( $\sim 7$ years old; Lovato \& Piper, 2015), asking the device questions such as, "What's your favorite healthy food?" or "What's your daddy's name?" (Lovato \& Piper, 2015, p. 337) and attributing human-like qualities to the device "I know he likes apples, just like I do" (Garg \& Sengupta, 2020). When the DVA does not respond to children's personified statements, questions or conversational pleasantries with like-minded statements, young children become visibly upset with the DVA, much like they would with a human. One reason for this behavior with digital informants is that some young children believe a human resides inside the device (Lovato et al., 2019) or that the device is controlled by a human (Festerling \& Siraj, 2020), and thus try to ascribe human-like morals, values, and intentions to the devices. Such belief decreases as children age but nonetheless bears the question of ontology.

Recently, cognitive scientists tasked themselves with this question, investigating children's understanding of what it means to be a human versus what it means to be a machine (Festerling \& Siraj, 2020). Analyzing interactions between DVAs and children between 6 and 10 years old, Festerling and Siraj (2020) report a robust ontological hierarchy with machines subservient to humans. They argue that despite children's personification of these devices, children do not feel obligated to interact with the devices in a morally respectable way, forgoing typical norms required for interaction with humans.

Festerling and Siraj's investigation is important to consider in light of the broader purpose of this review. Specifically, how do morality, likeness, and ontology affect willingness to trust DVAs relative to humans? Based on findings from the trust-in-testimony work, children under the age of 4 are more likely to selectively trust humans relative to DVAs because they prioritize social characteristics (e.g., likeness, humans being in group) over epistemic characteristics (e.g., accuracy, Lane et al., 2013; Tong et al., 2020). While Danovitch and Alzahabi (2013) suggest children may be able to override their accuracy bias earlier with digital informants than human informants, more work is needed to determine whether this finding was a product of their sample or if it generalizes. Thus, until more empirical evidence exists, the current hypothesis remains that children under 4 years are more likely to prefer human informants. Older children $(<5$ years) and adults, however, are more likely to opt for DVAs, and other technological informants, relative to humans (Danovitch, 2019; Wang et al., 2019) because they prioritize epistemic characteristics relative to in-group membership, morality, and likeness, dovetailing with Festerling and Siraj's findings.

As for digital informants, children as young as 3 years old consistently choose a reliable, accurate digital informant over an inconsistent, inaccurate digital informant (Danovitch \& Alzahabi, 2013), diverging from work investigating human informants such 
that young children appear to be able to override their accuracy bias earlier with digital informants than human informants.

\section{Summary}

Children use traits such as confidence and benevolence to evaluate informants when they lack requisite prior knowledge, favoring confident (e.g., Sabbagh \& Shafman, 2009), benevolent (Nguyen et al., 2016) informants. One could argue DVAs may be a better informant because their lack of human-like properties prevents them from clouding their testimony with emotions or morals. The absence of being human could be beneficial in that children could bypass evaluation of these characteristics when questioning DVAs, implying that children could accept new and/or unexpected testimony from DVAs more frequently than humans because they would not need to worry about being deceived. Yet, the work reviewed here suggests DVAs fail to meet children's social-characteristic expectations (i.e., confidence, morality). DVAs cannot, for instance, adequately discern realities between imaginary entities and scientific phenomena, responding to both in ways that suggest doubt exists in their provided testimony and subsequently decreasing the likelihood of trust in the devices (Basu, 2019). Thus, in using algorithms designed to make the devices sound human, the responses lose the expected sterile, inherently accurate nature that should come with the ability to provide internet-search responses in mere seconds (Ferrand et al., 2020; Tabassum et al., 2019).

Further, when children personify DVAs, they expect the devices to respond in a comprehensible, human-like manner, and when these types of responses are not provided, children may become visibly upset with the device (Festerling \& Siraj, 2020), decreasing the likelihood that children will continue to query DVAs relative to humans (Frazier et al., 2009). Reconciling these findings with empirical work that suggests children believe DVAs are subservient to humans and thus more apt to correctly respond to commands, requires further investigation. Young children ( $>4$ years) are more likely to rely on social characteristics (e.g., likeness, morality) than epistemic characteristics to evaluate trustworthiness, meaning they are more likely to query fellow humans than DVAs because they are in-group members. Thus, the belief that DVAs' purpose is respond to human command is more likely to be used as an evaluator by older children, who opt for epistemic characteristics (i.e., accuracy) to evaluate informant trustworthiness.

\section{Discussion}

Children rely on verbal testimony from trustworthy informants when they lack the prior knowledge necessary to make sense of the world (Harris, 2012; Hirsch, 2018; Kelemen et al., 2014). Thus, questions are an important mechanism for knowledge development, but they are only as powerful as the testimony they elicit. Children are selective in who they query and accept subsequent testimony from, especially when their first-hand explanations appear much more salient than abstract testimonial explanations (e.g., Gelman, 2009). In situations like these, children use epistemic and social characteristics to evaluate an informant's competence.

A significant body of work ("trust-in-testimony" studies, see Harris, 2012; Tong et al., 2020) has investigated the characteristics children use to evaluate humans' trustworthiness, suggesting children under the age of 4 are more likely to rely on humans' social characteristics (e.g., confidence, benevolence) than epistemic characteristics (e.g., accuracy, expertise) when making trust evaluations (e.g., Harris, 2012; Harris \& Koenig, 2006; Tong et al., 2020) with a developmental transition to weighting epistemic characteristics more heavily as they age. However, the work investigating the characteristics of digital informants, like DVAs, is far less advanced. Only one study (Danovitch \& Alzahabi, 2013) experimentally manipulates digital-informant characteristics within a trust-in-testimony paradigm. Consequently, comparison of children's preferences for human or digital informants is lagging — despite the prevalence of digital informants in children's daily lives (Beneteau et al., 2019). Thus, the purpose of this review was to evaluate several characteristics children typically use to evaluate trust in humans as a means to determine whether DVAs meet these expectations, providing recommendations for both future inquiry and DVA.

Based on the work reviewed here, children of all ages may be reluctant to trust DVAs, favoring humans as the more trustworthy source. Though DVAs are expected to provide quick, accurate responses to questions (Tabassum et al., 2019), DVAs are not always accurate (Ferrand et al., 2020) nor are they able to consistently provide explanatory responses to children's questions (Lovato et al., 2019) — an important consideration as children are likely to persist in asking questions again until a satisfactory, explanatory response is received (Frazier et al., 2009). This creates a problematic series of events in which children assume DVAs can follow sequenced conversations, leaving out contextual information, asking questions based on prior conversations, and subsequently getting visibly upset when DVAs are unable to function in these ways (e.g., Festerling \& Siraj, 2020; Lovato et al., 2019). Improving DVAs' ability to answer how and why questions beyond the current 50\% (Lovato et al., 2019) is an important first step in welcoming children into the fold as a valued user, particularly for older children who value accuracy and expertise above social characteristics such as morality and likeness. It may be the case that children who frequently experience DVAs failing to meet their expected needs will opt out of using these devices as knowledge sources in the future. Thus, more consistent, explanatory responses are needed-even further, providing a feature that would allow DVAs to target responses to their user (i.e., child vs. adult) would be useful.

Moreover, features that are expected to favor trustworthiness in DVAs, such as providing unbiased responses, are also in need of improvement. The research reviewed here suggests DVA responses can convey bias, doubt, and confidence much like a human's response (e.g., Jaswal, 2004; Jaswal \& Malone, 2007; Lovato et al., 2019) via sociopragmatic cues such as verbal modifiers (e.g., "I believe"). Such cues are particularly problematic for young children who typically lean on social characteristics rather than epistemic characteristics to evaluate informant trust. Children under the age of 4 are likely to personify these devices, believing they are operated by a human either inside the device or in the ether (Garg \& Sengupta, 2020; Lovato \& Piper, 2015) because they have a limited understanding of how the internet and these devices function. This personification and limited functional understanding may lead young children to apply the social characteristics they typically use to evaluate human trustworthiness to DVAs as well, again resulting in either (a) children becoming frustrated and upset when the devices do not respond to this personification in a way 
that is deemed to be acceptable (Festerling \& Siraj, 2020) and (b) potentially reducing the likelihood they will continue to seek information from these devices when the provided responses appear to convey doubt and a lack of confidence (e.g., "I believe in unicorns"; Lovato et al., 2019).

Though some have feared the ubiquity of technology would "mean the end of [human] conversation as we know it" (Ephron, 2008), the work reviewed here suggests that the technology available does not yet provide satisfactory responses to children's inquiry. Children expect coherent, frequent explanations to their questions, which DVAs cannot currently provide. DVAs should possess the requisite knowledge necessary to respond to children's questions in a variety of domains, but the inability to share that information in a meaningful way indicates that humans hold on to their role as preferred informants - at least for now. Further research is needed in this domain to continue exploring children's trust in digital devices and how these devices may be augmented to improve child-DVA interaction. Manipulating epistemic and social characteristics of DVAs in experimental paradigms like the work done in the trust in testimony literature would be highly informative. It could provide insight into whether children are able to identify and use these characteristics to evaluate the competence of DVAs. If they are indeed able, investigating humans and DVAs in the same paradigm would be the next step.

\section{References}

Allum, N., Sturgis, P., Tabourazi, D., \& Brunton-Smith, I. (2008). Science knowledge and attitudes across cultures: A meta-analysis. Public Understanding of Science, 17(1), 35-54. https://doi.org/10.1177/096366 2506070159

Barocas, S., \& Selbst, A. D. (2016). Big data's disparate impact. California Law Review, 104(3), Article 671. https://doi.org/10.15779/Z38BG31

Basu, T. (2019). Why kids don't trust Alexa. MIT Technology Review.

Beneteau, E., Richards, O. K., Zhang, M., Kientz, J. A., Yip, J., \& Hiniker, A. (2019, May). Communication breakdowns between families and Alexa. In S. Brewster \& G. Fitzpatrick (Eds.), Proceedings of the 2019 CHI conference on human factors in computing systems (pp. 1-13). Association for Computing Machinery.

Birch, S. A., Vauthier, S. A., \& Bloom, P. (2008). Three- and four-year-olds spontaneously use others' past performance to guide their learning. Cognition, 107(3), 1018-1034. https://doi.org/10.1016/j.cognition.2007 .12 .008

Bruner, J. S. (1957). On perceptual readiness. Psychological Review, 64(2), 123-152. https://doi.org/10.1037/h0043805

Caliskan, A., Bryson, J. J., \& Narayanan, A. (2017). Semantics derived automatically from language corpora contain human-like biases. Science, 356(6334), 183-186. https://doi.org/10.1126/science.aal4230

Callanan, M. A., \& Oakes, L. M. (1992). Preschoolers' questions and parents' explanations: Causal thinking in everyday activity. Cognitive Development, 7(2), 213-233. https://doi.org/10.1016/0885-2014(92) 90012-G

Carlson, S. M., Moses, L. J., \& Breton, C. (2002). How specific is the relation between executive function and theory of mind? Contributions of inhibitory control and working memory. Infant and Child Development: An International Journal of Research and Practice, 11(2), 73-92. https:// doi.org/10.1002/icd.298

Carlson, S. M., Moses, L. J., \& Hix, H. R. (1998). The role of inhibitory processes in young children's difficulties with deception and false belief. Child Development, 69(3), 672-691. https://doi.org/10.1111/j.1467-8624 .1998.00672.x
Chan, C. C., \& Tardif, T. (2013). Knowing better: the role of prior knowledge and culture in trust in testimony. Developmental Psychology, 49(3), 591.

Chan, C. C., \& Tardif, T. (2013). Knowing better: The role of prior knowledge and culture in trust intestimony. Developmental Psychology, 49(3), 591-601. https://doi.org/10.1037/a0031336

Cheng, Y., Yen, K., Chen, Y., Chen, S., \& Hiniker, A. (2018, June). Why doesn't it work? voice-driven interfaces and young children's communication repair strategies. In M. Giannakos, L. Jaccheri, \& M. Divitini (Eds.), Proceedings of the 17th ACM conference on interaction design and children (pp. 337-348). Association for Computing Machinery.

Chouinard, M. M. (2007). Children's questions: A mechanism for cognitive development. Monographs of the Society for Research in Child Development, 72(1), vii-ix.

Cook, J., Oreskes, N., Doran, P. T., Anderegg, W. R., Verheggen, B., Maibach, E. W., Carlton, J. S., Lewandowsky, S., Skuce, A. G., Green, S. A., Nuccitelli, D., Jacobs, P., Richardson, M., Winkler, B., Painting, R., \& Nuccitelli, D. (2016). Consensus on consensus: A synthesis of consensus estimates on human-caused global warming. Environmental Research Letters, 11(4), Article 048002. https://doi.org/10.1088/1748-9326/11/4/048002

Corriveau, K. H., \& Harris, P. L. (2010). Preschoolers (sometimes) defer to the majority in making simple perceptual judgments. Developmental Psychology, 46(2), 437-445. https://doi.org/10.1037/a0017553

Corriveau, K. H., Harris, P. L., Meins, E., Fernyhough, C., Arnott, B., Elliott, L., Liddle, B., Hearn, A., Vittorini, L., \& de Rosnay, M. (2009). Young children's trust in their mother's claims: Longitudinal links with attachment security in infancy. Child Development, 80(3), 750-761. https:// doi.org/10.1111/j.1467-8624.2009.01295.x

Corriveau, K. H., Pickard, K., \& Harris, P. L. (2011). Preschoolers trust particular informants when learning new names and new morphological forms. British Journal of Developmental Psychology, 29(1), 46-63. https://doi.org/10.1348/2044-835X.002009

Csibra, G., \& Gergely, G. (2009). Natural pedagogy. Trends in Cognitive Sciences, 13(4), 148-153. https://doi.org/10.1016/j.tics.2009.01.005

Danovitch, J. H. (2019). Growing up with Google: How children's understanding and use of internet-based devices relates to cognitive development. Human Behavior and Emerging Technologies, 1(2), 81-90. https:// doi.org/10.1002/hbe2.142

Danovitch, J. H., \& Alzahabi, R. (2013). Children show selective trust in technological informants. Journal of Cognition and Development, 14(3), 499-513. https://doi.org/10.1080/15248372.2012.689391

Danovitch, J. H., \& Keil, F. C. (2008). Young humeans: The role of emotions in children's evaluation of moral reasoning abilities. Developmental Science, 11(1), 33-39. https://doi.org/10.1111/j.1467-7687.2007.00657.x

de Rooij, W., Müller, V. J., \& Elliott, F. (2019). About. Alexa Answers. https://alexaanswers.amazon.com/about

Druga, S., Williams, R., Breazeal, C., \& Resnick, M. (2017, June). "Hey Google is it OK if I eat you?" initial explorations in child-agent interaction. In P. Blikstein \& D. Abrahamson (Eds.), Proceedings of the 2017 conference on interaction design and children (pp. 595-600). Association for Computing Machinery.

Dunn, J., \& Brown, J. R. (1993). Early conversations about causality: Content, pragmatics and developmental change. British Journal of Developmental Psychology, 11(2), 107-123. https://doi.org/10.1111/j.2044835X.1993.tb00591.x

Einav, S., \& Robinson, E. J. (2010). Children's sensitivity to error magnitude when evaluating informants. Cognitive Development, 25(3), 218-232. https://doi.org/10.1016/j.cogdev.2010.04.002

Eisen, S., \& Lillard, A. S. (2016). Just Google it: Young children's preferences for touchscreens versus books in hypothetical learning tasks. Frontiers in Psychology, 7, Article 1431. https://doi.org/10.3389/fpsyg .2016 .01431

Eisen, S., \& Lillard, A. S. (2017). Young children's thinking about touchscreens versus other media in the US. Journal of Children and Media, 11(2), 167-179. https://doi.org/10.1080/17482798.2016.1254095 
Ephron, N. (2008). The chicken doup chronicles. The New York Times. https://www.nytimes.com/2008/01/13/opinion/13ephron.html

Ericsson, K. A. (2017). Expertise and individual differences: The search for the structure and acquisition of experts' superior performance. Wiley Interdisciplinary Reviews: Cognitive Science, 8(1-2), Article e1382. https://doi.org/10.1002/wcs.1382

Ferrand, J., Hockensmith, R., Houghton, R. F., \& Walsh-Buhi, E. R. (2020). Evaluating smart assistant responses for accuracy and misinformation regarding human papillomavirus vaccination: Content analysis study. Journal of Medical Internet Research, 22(8), Article e19018. https:// doi.org/10.2196/19018

Festerling, J., \& Siraj, I. (2020). Alexa, what are you? Exploring primary school children's ontological perceptions of digital voice assistants in open interactions. Human Development, 64(1), 26-43. https://doi.org/10.1159/ 000508499

Fiske, S. T., Cuddy, A. J., \& Glick, P. (2007). Universal dimensions of social cognition: Warmth and competence. Trends in Cognitive Sciences, 11(2), 77-83. https://doi.org/10.1016/j.tics.2006.11.005

Frazier, B. N., Gelman, S. A., \& Wellman, H. M. (2009). Preschoolers' search for explanatory information within adult-child conversation. Child Development, 80(6), 1592-1611. https://doi.org/10.1111/j.1467-8624 .2009.01356.x

Fu, G., Heyman, G. D., Chen, G., Liu, P., \& Lee, K. (2015). Children trust people who lie to benefit others. Journal of Experimental Child Psychology, 129, 127-139. https://doi.org/10.1016/j.jecp.2014.09.006

Fusaro, M., \& Harris, P. L. (2008). Children assess informant reliability using bystanders' non-verbal cues. Developmental Science, 11(5), 771777. https://doi.org/10.1111/j.1467-7687.2008.00728.x

Garg, R., \& Sengupta, S. (2020). He is just like me: A study of the long-term use of smart speakers by parents and children. Proceedings of the ACM on Interactive, Mobile, Wearable and Ubiquitous Technologies, 4(1), 1-24. https://doi.org/10.1145/3381002

Gauvain, M., \& Munroe, R. L. (2020). 10 children's questions in social and cultural perspective. In L. Payne Butler, S. Ronaford, \& K. Corriveau (Eds.), The questioning child: Insights from psychology and education (p. 183). Cambridge University Press.

Gauvain, M., Munroe, R. L., \& Beebe, H. (2013). Children's questions in crosscultural perspective: A four-culture study. Journal of Cross-Cultural Psychology, 44(7), 1148-1165. https://doi.org/10.1177/0022022113485430

Gelman, S. A. (2009). Learning from others: Children's construction of concepts. Annual Review of Psychology, 60(1), 115-140. https://doi.org/ 10.1146/annurev.psych.59.103006.093659

Google. (2021, February 16). How Google search works for beginners | Google search central. Google Developers. https://developers.google .com/search/docs/basics/how-search-works

Goupil, L., Romand-Monnier, M., \& Kouider, S. (2016). Infants ask for help when they know they don't know. Proceedings of the National Academy of Sciences of the United States of America, 113(13), 3492-3496. https:// doi.org/10.1073/pnas.1515129113

Grice, H. P. (1975). Logic and conversation. In P. Cole \& J. Morgan (Eds.), Speech acts (pp. 41-58). Brill.

Harris, P. L. (2012). Trusting what you're told: How children learn from others. Harvard University Press. https://doi.org/10.4159/harvard .9780674065192

Harris, P. L., \& Koenig, M. A. (2006). Trust in testimony: How children learn about science and religion. Child Development, 77(3), 505-524. https:// doi.org/10.1111/j.1467-8624.2006.00886.x

Henrich, J., Heine, S. J., \& Norenzayan, A. (2010). The weirdest people in the world? Behavioral and Brain Sciences, 33(2-3), 61-83. https:// doi.org/10.1017/S0140525X0999152X

Hickling, A. K., \& Wellman, H. M. (2001). The emergence of children's causal explanations and theories: Evidence from everyday conversation. Developmental Psychology, 37(5), 668-683. https://doi.org/10.1037/ 0012-1649.37.5.668
Hirsch, E. D. (2018). Why knowledge matters: Rescuing our children from failed educational theories. Harvard Education Press.

Hoy, M. B. (2018). Alexa, Siri, Cortana, and more: An introduction to voice assistants. Medical Reference Services Quarterly, 37(1), 81-88. https:// doi.org/10.1080/02763869.2018.1404391

Issacs, N. (1930a). Children's "why” questions. In S. Issacs (Ed.), Intellectual growth in young children (pp. 291-349). Routledge and Sons.

Issacs, S. (1930b). Intellectual growth in young children. George Routledge and Sons.

Jaccard, J. (1981). Toward theories of persuasion and belief change. Journal of Personality and Social Psychology, 40(2), 260-269. https://doi.org/10 $.1037 / 0022-3514.40 .2 .260$

Jaswal, V. K. (2004). Don't believe everything you hear: Preschoolers' sensitivity to speaker intent in category induction. Child Development, 75(6), 1871-1885. https://doi.org/10.1111/j.1467-8624.2004.00822.x

Jaswal, V. K. (2010). Believing what you're told: Young children's trust in unexpected testimony about the physical world. Cognitive Psychology, 61(3), 248-272. https://doi.org/10.1016/j.cogpsych.2010.06.002

Jaswal, V. K., \& Malone, L. S. (2007). Turning believers into skeptics: 3-year-olds' sensitivity to cues to speaker credibility. Journal of Cognition and Development, 8(3), 263-283. https://doi.org/10.1080/1524837 0701446392

Jaswal, V. K., Pérez-Edgar, K., Kondrad, R. L., Palmquist, C. M., Cole, C. A., $\&$ Cole, C. E. (2014). Can't stop believing: Inhibitory control and resistance to misleading testimony. Developmental Science, 17(6), 965-976. https:// doi.org/10.1111/desc. 12187

Karmiloff-Smith, A., \& Inhelder, B. (1974). If you want to get ahead, get a theory. Cognition, 3(3), 195-212. https://doi.org/10.1016/0010-0277(74) 90008-0

Keil, F. C., Stein, C., Webb, L., Billings, V. D., \& Rozenblit, L. (2008). Discerning the division of cognitive labor: An emerging understanding of how knowledge is clustered in other minds. Cognitive Science, 32(2), 259300. https://doi.org/10.1080/03640210701863339

Kelemen, D., Emmons, N. A., Seston Schillaci, R., \& Ganea, P. A. (2014). Young children can be taught basic natural selection using a picturestorybook intervention. Psychological science, 25(4), 893-902. https:// doi.org/10.1177/0956797613516009

Kinzler, K. D., Corriveau, K. H., \& Harris, P. L. (2011). Children's selective trust in native-accented speakers. Developmental Science, 14(1), 106-111. https://doi.org/10.1111/j.1467-7687.2010.00965.x

Kodama, C., St Jean, B., Subramaniam, M., \& Taylor, N. G. (2017). There's a creepy guy on the other end at Google!: Engaging middle school students in a drawing activity to elicit their mental models of Google. Information Retrieval Journal, 20(5), 403-432. https://doi.org/10.1007/s10791-0179306-x

Koenecke, A., Nam, A., Lake, E., Nudell, J., Quartey, M., Mengesha, Z., Toups, C., Rickford, J. R., Jurafsky, D., \& Goel, S. (2020). Racial disparities in automated speech recognition. Proceedings of the National Academy of Sciences of the United States of America, 117(14), 76847689. https://doi.org/10.1073/pnas.1915768117

Koenig, M. A., Clément, F., \& Harris, P. L. (2004). Trust in testimony: Children's use of true and false statements. Psychological Science, 15(10), 694-698. https://doi.org/10.1111/j.0956-7976.2004.00742.x

Kurkul, K. E. (2015). Question, explanation, follow-up: a global mechanism for learning from others? [Doctoral dissertation]. Boston University.

Kurkul, K. E., \& Corriveau, K. H. (2018). Question, explanation, follow-up: A mechanism for learning from others? Child Development, 89(1), 280294. https://doi.org/10.1111/cdev.12726

Lane, J. D., Wellman, H. M., \& Gelman, S. A. (2013). Informants' traits weigh heavily in young children's trust in testimony and in their epistemic inferences. Child Development, 84(4), 1253-1268. https://doi.org/10 $.1111 /$ cdev.12029

Lovato, S., \& Piper, A. M. (2015). "Siri, is this you?" Understanding young children's interactions with voice input systems. In M. Bers \& G. Revelle 
(Eds.), Proceedings of the 14th international conference on interaction design and children (pp. 335-338). Association for Computing Machinery.

Lovato, S. B., Piper, A. M., \& Wartella, E. A. (2019). Hey Google, do unicorns exist? Conversational agents as a path to answers to children's questions. In J. Fails (Eds.), Proceedings of the 18th ACM international conference on interaction design \& children (pp. 301-313). Association for Computing Machinery.

Luchins, A. S. (1942). Mechanization in problem solving. Psychological Monographs, 54(6), i-95. https://doi.org/10.1037/h0093502.

Lutz, D. J., \& Keil, F. C. (2002). Early understanding of the division of cognitive labor. Child Development, 73(4), 1073-1084. https://doi.org/10 $.1111 / 1467-8624.00458$

Ma, L., \& Ganea, P. A. (2010). Dealing with conflicting information: Young children's reliance on what they see versus what they are told. Developmental Science, 13(1), 151-160. https://doi.org/10.1111/j.1467-7687 .2009.00878.x

MacWhinney, B., \& Snow, C. (1985). The child language data exchange system. Journal of Child Language, 12(2), 271-295. https://doi.org/10 .1017/S0305000900006449

Marchant, G., Robinson, J., Anderson, U., \& Schadewald, M. (1991). Analogical transfer and expertise in legal reasoning. Organizational Behavior and Human Decision Processes, 48(2), 272-290. https:// doi.org/10.1016/0749-5978(91)90015-L

Mascaro, O., \& Sperber, D. (2009). The moral, epistemic, and mindreading components of children's vigilance towards deception. Cognition, 112(3), 367-380. https://doi.org/10.1016/j.cognition.2009 .05 .012

Masson, M. E., Bub, D. N., \& Lalonde, C. E. (2011). Video-game training and naïve reasoning about object motion. Applied Cognitive Psychology, 25(1), 166-173. https://doi.org/10.1002/acp.1658

McNeil, N. M., \& Alibali, M. W. (2002). A strong schema can interfere with learning: The case of children's typical addition schema. In Proceedings of the annual meeting of the cognitive science society (Vol. 24, No. 24). https://escholarship.org/uc/item/3pv2h5pt

Mikropoulos, T. A., Misailidi, P., \& Bonoti, F. (2003). Attributing human properties to computer artifacts: Developmental changes in children's understanding of the animate-inanimate distinction. Psychology. 10(1), 53-64.

Mori, M., MacDorman, K. F., \& Kageki, N. (2012). The uncanny valley [from the field]. IEEE Robotics \& Automation Magazine, 19(2), 98-100. https://doi.org/10.1109/MRA.2012.2192811

Nguyen, S. P., Gordon, C. L., Chevalier, T., \& Girgis, H. (2016). Trust and doubt: An examination of children's decision to believe what they are told about food. Journal of Experimental Child Psychology, 144, 66-83. https://doi.org/10.1016/j.jecp.2015.10.015

Noles, N. S., Danovitch, J., \& Shafto, P. (2015). Children's trust in technological and human informants. In D. C. Noelle, R. Dale, A. S. Warlaumont, J. Yoshimi, T. Matlock, C. D. Jennings, \& P. P. Maglio (Eds.) Proceedings of the 37th Annual Meeting of the Cognitive Science Society. Cognitive Science Society.

Pan, B., Hembrooke, H., Joachims, T., Lorigo, L., Gay, G., \& Granka, L. (2007). In Google we trust: Users' decisions on rank, position, and relevance. Journal of Computer-Mediated Communication, 12(3), 801823. https://doi.org/10.1111/j.1083-6101.2007.00351.x

Pasquini, E. S., Corriveau, K. H., Koenig, M., \& Harris, P. L. (2007). Preschoolers monitor the relative accuracy of informants. Developmental Psychology, 43(5), 1216-1226. https://doi.org/10.1037/0012-1649 .43.5.1216

Pesch, A., Suárez, S., \& Koenig, M. A. (2018). Trusting others: Shared reality in testimonial learning. Current Opinion in Psychology, 23, 38-41. https://doi.org/10.1016/j.copsyc.2017.11.009

Piaget, J. (1926). The thought and language of the child. New York: Harcourt, Brace, and Company.
Purington, A., Taft, J. G., Sannon, S., Bazarova, N. N., \& Taylor, S. H. (2017, May). "Alexa is my new BFF" social roles, user satisfaction, and personification of the amazon echo. In G. Mark \& S. Fussel (Eds.), Proceedings of the 2017 CHI conference extended abstracts on human factors in computing systems (pp. 2853-2859). Association for Computing Machinery.

Ronfard, S., \& Lane, J. D. (2018). Preschoolers continually adjust their epistemic trust based on an informant's ongoing accuracy. Child Development, 89(2), 414-429. https://doi.org/10.1111/cdev.12720

Rousseau, J.-J. (1999). Education (M. A. Barbara Foxley, Trans.). J. M. Dent and Sons/E. P. Dutton. (Original work published 1921).

Sabbagh, M. A., \& Baldwin, D. A. (2001). Learning words from knowledgeable versus ignorant speakers: Links between preschoolers' theory of mind and semantic development. Child Development, 72(4), 1054-1070. https://doi.org/10.1111/1467-8624.00334

Sabbagh, M. A., \& Shafman, D. (2009). How children block learning from ignorant speakers. Cognition, 112(3), 415-422. https://doi.org/10.1016/j .cognition.2009.06.005

Schulz, L. E., \& Bonawitz, E. B. (2007). Serious fun: Preschoolers engage in more exploratory play when evidence is confounded. Developmental Psychology, 43(4), 1045-1050. https://doi.org/10.1037/0012-1649.43 .4 .1045

Shtulman, A. (2017). Scienceblind: Why our intuitive theories about the world are so often wrong. Hachette UK.

Stephens, E., Suarez, S., \& Koenig, M. (2015). Early testimonial learning: Monitoring speech acts and speakers. Advances in Child Development and Behavior, 48, 151-183. https://doi.org/10.1016/bs.acdb.2014.11.004

Sweeney, L. (2013). Discrimination in online ad delivery. Queue, 11(3), 1029. https://doi.org/10.1145/2460276.2460278

Tabassum, M., Kosiński, T., Frik, A., Malkin, N., Wijesekera, P., Egelman, S., \& Lipford, H. R. (2019). Investigating users' preferences and expectations for always-listening voice assistants. Proceedings of the ACM on Interactive, Mobile, Wearable and Ubiquitous Technologies, 3(4), 1-23. https://doi.org/10.1145/3369807

Tamis-LeMonda, C. S., Way, N., Hughes, D., Yoshikawa, H., Kalman, R. K., \& Niwa, E. Y. (2008). Parents' goals for children: The dynamic coexistence of individualism and collectivism in cultures and individuals. Social Development, 17(1), 183-209.

Tizard, B., Hughes, M., Carmichael, H., \& Pinkerton, G. (1983). Children's questions and adults' answers. Journal of Child Psychology and Psychiatry, and Allied Disciplines, 24(2), 269-281. https://doi.org/10.1111/j .1469-7610.1983.tb00575.x

Tong, Y., Wang, F., \& Danovitch, J. (2020). The role of epistemic and social characteristics in children's selective trust: Three meta-analyses. Developmental Science, 23(2), Article e12895. https://doi.org/10.1111/desc.12895

Van Duuren, M., Dossett, B., \& Robinson, D. (1998). Gauging children's understanding of artificially intelligent objects: A presentation of "counterfactuals." International Journal of Behavioral Development, 22(4), 871889. https://doi.org/10.1080/016502598384207

Vanderbilt, K. E., Heyman, G. D., \& Liu, D. (2014). In the absence of conflicting testimony young children trust inaccurate informants. Developmental Science, 17(3), 443-451. https://doi.org/10.1111/desc.12134

Vanderbilt, K. E., Liu, D., \& Heyman, G. D. (2011). The development of distrust. Child development, 82(5), 1372-1380.

Wang, F., Tong, Y., \& Danovitch, J. (2019). Who do I believe? Children's epistemic trust in internet, teacher, and peer informants. Cognitive Development, 50, 248-260. https://doi.org/10.1016/j.cogdev.2019.05.006

West, M., Kraut, R., \& Ei Chew, H. (2019). I'd blush if I could: Closing gender divides in digital skills through education. United Nations Educational, Scientific, and Cultural Organization (UNESCO).

Wiggers, K. (2019, November 3). Amazon is poorly vetting Alexa's usersubmitted answers. VentureBeat. https://venturebeat.com/2019/11/01/ amazon-alexa-answers-vetting-user-questions/

Williams, B. R., Ponesse, J. S., Schachar, R. J., Logan, G. D., \& Tannock, R. (1999). Development of inhibitory control across the life span. 
Developmental Psychology, 35(1), 205-213. https://doi.org/10.1037/ 0012-1649.35.1.205

Yarosh, S., Thompson, S., Watson, K., Chase, A., Senthilkumar, A., Yuan, Y., \& Brush, A. B. (2018, June). Children asking questions: speech interface reformulations and personification preferences. In M. Giannakos, L. Jaccheri, \& M. Divitini (Eds.), Proceedings of the 17th ACM conference on interaction design and children (pp. 300-312). Association for Computing Machinery.

Received November 24, 2020 Revision received July 16, 2021 Accepted July 17, 2021 